\title{
Short-term therapy with simvastatin reduces inflammatory mediators and heart inflammation during the acute phase of experimental Chagas disease
}

\author{
Rafael Rodrigues Silva ${ }^{1}$, Deena Shrestha-Bajracharya', Camila Megale Almeida-Leite ${ }^{2}$, \\ Rômulo Leite $^{3}$, Maria Terezinha Bahia ${ }^{1,2}$, Andre Talvani ${ }^{1,2} /+$ \\ 'Núcleo de Pesquisas em Ciências Biológicas ²Departamento de Ciências Biológicas \\ ${ }^{3}$ Escola de Farmácia, Universidade Federal de Ouro Preto, Ouro Preto, MG, Brasil
}

Trypanosoma cruzi infection induces progressive cardiac inflammation that leads to fibrosis and modifications in the heart architecture and functionality. Statins, such as 3-hydroxy-3-methylglutaryl coenzyme A (HMG CoA) reductase inhibitors, have been studied due to their pleiotropic roles in modulating the inflammatory response. Our goal was to evaluate the effects of simvastatin on the cardiac inflammatory process using a cardiotropic strain of T. cruzi in a murine model of Chagas cardiomyopathy. C57BL/6 mice were infected with 500 trypomastigotes of the Colombian strain of T. cruzi and treated with an oral dose of simvastatin $(20 \mathrm{mg} / \mathrm{Kg} / \mathrm{day})$ for one month and inflammatory and morphometric parameters were subsequently evaluated in the serum and in the heart, respectively. Simvastatin reduced the total cholesterol and inflammatory mediators (interferon-gamma, tumour necrosis factoralpha, CCL2 and CCL5) in the serum and in the heart tissue at 30 days post-infection. Additionally, a proportional reduction in heart weight and inflammatory infiltration was observed. Simvastatin also reduced epimastigote proliferation in a dose-dependent manner in vitro and was able to reduce blood trypomastigotes and heart amastigote nests during the acute phase of Chagas disease in vivo. Based on these data, we conclude that simvastatin exerts a modulatory effect on the inflammatory mediators that are elicited by the Colombian strain of T. cruzi and ameliorates the heart damage that is observed in a murine model of Chagas disease.

Key words: Chagas cardiomyopathy - Trypanosoma cruzi - simvastatin - chemokines - inflammation

Chagas cardiomyopathy $(\mathrm{CC})$ is a chronic clinical manifestation that is caused by the protozoan Trypanosoma cruzi. This protozoan induces persistent inflammation comprised of neutrophils, macrophages, $\mathrm{CD} 4^{+}$and $\mathrm{CD} 8^{+} \mathrm{T}$ cells (Reis et al. 1993, Brener \& Gazzinelli 1997) that culminates in myocarditis, fibrosis and changes in the heart architecture and functionality. This illness, which affects approximately 10 million individuals in Latin America, is characterised by persistent inflammatory remodelling of the heart tissue and is becoming the most common form of progressive, non-ischaemic heart disease worldwide (Prata 2001, WHO 2010). Both systemically and at chronic inflammatory foci, inflammatory cells release inflammatory cytokines, such as interferon-gamma (IFN- $\gamma$ ) and tumour necrosis factor-alpha (TNF- $\alpha$ ) and various chemokines (e.g., CCL2, CCL3 and CCL5) that assist in the control of the parasite infection. However, these effectors also drastically affect heart tissue integrity and increase the cardiac inflammatory response, leading to a worsening of the disease phenotype (Talvani \& Teixeira 2011).

Financial support: CNPq/TWAS, FAPEMIG, ISID/EUA

+Corresponding author: talvani@nupeb.ufop.br

AT, MTB and RL are fellowship from CNPq.

CMA-L current address: Departamento de Morfologia, Universidade Federal de Minas Gerais, Belo Horizonte, MG, Brasil.

Received 30 August 2011

Accepted 2 February 2012
The ability of the host to control the infection may dictate the balance that exists between the inflammatory disease course and the typical regulatory immune response. Newly developed cardiovascular therapeutics (e.g., ACE-inhibitors and beta-blockers) have been shown to reduce inflammatory infiltration, fibrosis, cardiac output ventricular function and circulating inflammatory cytokines and chemokines in experimental and human studies (Leon et al. 2003, Botoni et al. 2007, Paula-Costa et al. 2010, Coelho dos Santos et al. 2010). More recently, by blocking the conversion of 3-hydroxy-3methylglutaryl coenzyme A (HMG CoA) to mevalonate, HMG CoA reductase inhibitors (statins) have emerged as potent inhibitors of cholesterol and isoprenoid biosynthesis (Liao 2002). Furthermore, the pleiotropic effects of statins have been associated with the inhibition of inflammatory cytokine synthesis, a reduction in ventricular remodelling and an improvement in endothelial cell function through the increased production of endothelial nitric oxide and a decrease in the release of endothelin-1 and other inflammatory mediators (Elrod \& Lefer 2005, Greer et al. 2006, Devaraj et al. 2007). Additionally, some studies have also suggested that the specific statin simvastatin may affect immune-mediated inflammation because of the documented ability of this statin to reduce the adhesion of inflammatory cells to the endothelium, inhibit leukocyte adhesion by direct interactions with the leukocyte-function antigen-1 and modulate the expression of the integrin dimer CD11b on monocytes. Simvastatin may also participate in the regulation of cy- 
tokine/chemokine gene expression and in the functioning of the innate and adaptive immune systems (Serrano et al. 2001, Cui et al. 2009, Bu et al. 2011).

The anti-inflammatory properties of statins are independent of their effects on cholesterol levels, but despite a favourable safety profile for short treatment with statins (Node et al. 2003), few studies have described the role of statins during the inflammatory events triggered by $T$. cruzi infection. Our aim is to evaluate the effect of simvastatin on cardiac inflammation using a cardiotropic strain of T. cruzi (Colombian) in a murine model and to assess the modulation of immune parameters and epimastigote replication by statins in vitro.

\section{MATERIALS AND METHODS}

Parasites - Blood trypomastigotes from the T. cruzi Colombian strain, which have a cardiac tropism and have been classified as discrete typing units I of $T$. cruzi (Zingales et al. 2009), were maintained through successive passages in Swiss mice at the Laboratory of Chagas disease, Federal University of Ouro Preto (UFOP), state of Minas Gerais, Brazil.

Experimental animals and infection - Male C57BL/6 mice weighing 18-20 g (50 days of age) from the Animal Facility at UFOP were inoculated intraperitoneally with 500 trypomastigotes from the $T$. cruzi Colombian strain. All procedures were performed in accordance with the guidelines issued by the Brazilian College of Animal Experimentation and these experiments were previously approved by the Ethic Committee in Animal Research at UFOP (CEUA) (protocol \#2009/28). Animals were fed commercial food and water ad libitum. The mouse parasitaemia was determined by collecting fresh blood from the tail vein on the 3rd day of infection and parasitaemia was analysed until no parasites were detectable in the blood.

Statin and treatment scheme - A previous set of experiments was performed to determine the toxicity of simvastatin (Sanval, SP, Brazil) treatment in mice $(\mathrm{n}=8$ / group) using a daily dose of 2, 20, 40 and $80 \mathrm{mg} / \mathrm{kg}$. A dose of $20 \mathrm{mg} / \mathrm{kg}$ was selected for the current study and administered daily in the evening to account for the circadian rhythm of statins. A new set of mice were divided into the following groups: (i) 10 mice infected with T. cru$z i$ receiving vehicle, (ii) 10 mice infected with $T$. cruzi and treated with simvastatin $(20 \mathrm{mg} / \mathrm{kg})$, (iii) 10 non-infected mice receiving vehicle only and (iv) 10 non-infected mice treated with simvastatin $(20 \mathrm{mg} / \mathrm{kg})$. This experiment was repeated twice and the survivors from the first and second experiments were grouped to obtain a total of 10 biological samples. Simvastatin was diluted in phosphate buffer (vehicle) for $15 \mathrm{~min}$ in an ultrasonic water bath and administered in the oropharyngeal cavity by gavage. This therapy was initiated on the same day as T. cruzi inoculation and continued for 30 days post-infection. Treatment was typically administered in the morning. The animals were euthanized on the afternoon of the 30th day.

In vitro effect of simvastatin on Trypanosoma cruzi To assess whether the HMG-CoA inhibitor simvastatin affects parasite survival in vitro, epimastigotes of the $\mathrm{Y}$ strain of $T$. cruzi were cultivated in liver infusion trip- tose (LIT) medium to a cellular density of $10^{6}$ epimastigotes per $\mathrm{mL}$, as previously described (Paula-Costa et al. 2010). Simvastatin (1.9 mM-1 M/mL) was mixed for 15 min in LIT medium using an ultrasonic bath, added to the parasite suspension and incubated at $28^{\circ} \mathrm{C}$. The surviving parasites were counted after $24 \mathrm{~h}$ and daily for seven days in a Neubauer chamber and the number of parasites was compared with that upon cultivation in LIT medium without drug. The tests were performed in triplicate and repeated twice.

ELISA for inflammatory mediators - Circulating levels of TNF- $\alpha$, IFN- $\gamma$, interleukin (IL)-10, regulated upon activation, normal $\mathrm{T}$ cell expressed and secreted (CCL5/ RANTES) and monocyte chemoattractant protein (CCL2/MCP-1) from simvastatin-treated and untreated mice were collected 30 days after infection from the orbital venous sinus $(0.5 \mathrm{~mL})$. After euthanasia, $100 \mathrm{mg}$ of cardiac tissue from each animal was homogenised in cold phosphate buffer and the supernatants were stored to evaluate the previously mentioned soluble inflammation mediators. For the analysis, the samples (serum and homogenate) were thawed and excess proteins were removed by acid/salt precipitation, as previously described (Lula et al. 2009). Briefly, equal volumes of serum and $1.2 \%$ trifluoracetic acid/1.35 M NaCl were mixed and incubated at room temperature for $10 \mathrm{~min}$ followed by centrifugation for $5 \mathrm{~min}$ at $10,000 \mathrm{rpm}$. The supernatants were adjusted for salt content $(0.14 \mathrm{M}$ sodium chloride and $0.01 \mathrm{M}$ sodium phosphate) and to a $\mathrm{pH}$ of 7.4 to determine the concentrations of the aforementioned murine soluble cytokines. TNF- $\alpha$, IFN- $\gamma$, IL-10 (BioSource International, Inc, CA, USA), CCL5 and CCL2 (R\&D Systems, Minneapolis, MN) levels were quantified by ELISA following the manufacturer's guidelines. All samples were measured in duplicate.

Cholesterol determination - Blood from 10 animals/ group (2 independent experiments) was collected at the time of euthanasia and serum was obtained after centrifugation $\left(3,500 \mathrm{rpm}\right.$ for $5 \mathrm{~min}$ at $\left.4^{\circ} \mathrm{C}\right)$ as previously described by Haraguchi et al. (2010). The total cholesterol content was assessed using an enzymatic kit (Doles, Brazil).

Morphometric and histopathology analysis - Animals were euthanized 30 days after infection and sections of the heart (half atrium and ventricle) from each mouse were collected for histopathology analysis. Tissue fragments were fixed in $10 \%$ buffered formalin solution, dehydrated, cleared and embedded in paraffin. Frozen tissue was cut into 4-mm-thick sections and stained with haematoxylin-eosin (H\&E) for the assessment of both inflammation and amastigote nests. Twenty fields from each H\&E stained section were randomly chosen and analysed at 40X magnification. A total area of $74.931 \mu \mathrm{m}^{2}$ was analysed, which is the equivalent area of 50 fields of analysed myocardium. The images were obtained using a Leica DM 5000 B microchamber vs. 2.4.0 R1 (Leica Application Suite, UK) and processed by the Leica QWin (V3) image analyser software. The inflammatory process was evaluated by a correlation index between the area $\left(\mu \mathrm{m}^{2}\right)$ of cellular nuclei observed in the heart tissue from non-infected compared with infected animals (either 
treated with simvastatin or untreated). This index corresponded to inflammatory leukocyte nuclei in addition to the background of cardiac cellular nuclei observed in data from non-infected mice, as previously shown (Caldas et al. 2008). Amastigote nests were also quantified by calculating the area occupied by parasites in the same sections used to quantify the inflammatory process.

Heart mass measurement - Hearts were carefully excised ex vivo and gently blotted on absorbent paper to remove blood from the ventricles before the wet weight measurements were calculated. The relative heart weight was calculated using the heart weight in $\mathrm{mg} /$ mouse body weight in grams $(\mathrm{mg} / \mathrm{g})$. This value was then used to evaluate the cardiac mass measurements obtained after 30 days of infection and after treatment with simvastatin in animals from two independent experiments $(\mathrm{n}=10)$.

Statistical analysis - The results of the serological assays, immune assays and morphological and histopathology parameters were analysed by non-parametric Newman-Keuls Multiple Comparison and Tukey's tests. A difference was considered significant if $p$ was equal to or less than 0.05 .

\section{RESULTS}

The effect of simvastatin on circulating and in vitro parasite levels and on surviving C57BL/6 mice - A doseresponse for simvastatin was investigated using 2, 20, 40 and $80 \mathrm{mg} / \mathrm{kg}$ of animal weight during 30 days of $T$. cruzi infection. High doses of simvastatin (40 and $80 \mathrm{mg} / \mathrm{kg}$ ) were observed to cause an elevated index of mortality on the 25th day of infection, which coincided with the day before peak parasitaemia was observed (Table). Among the animals treated with $2 \mathrm{mg}$ and $20 \mathrm{mg}$ of simvastatin, $60 \%$ and $40 \%$ mortality was observed, respectively, on the 25th day of infection, with no differences in the level of circulating parasites.
Assuming $20 \mathrm{mg} / \mathrm{kg} /$ day as the ideal dose of simvastatin (due to the decreased mortality), we identified a significant reduction in the level of circulating parasites during peak parasitaemia on the 26th day and in the previous three days (Fig. 1A). Simvastatin did not cause an
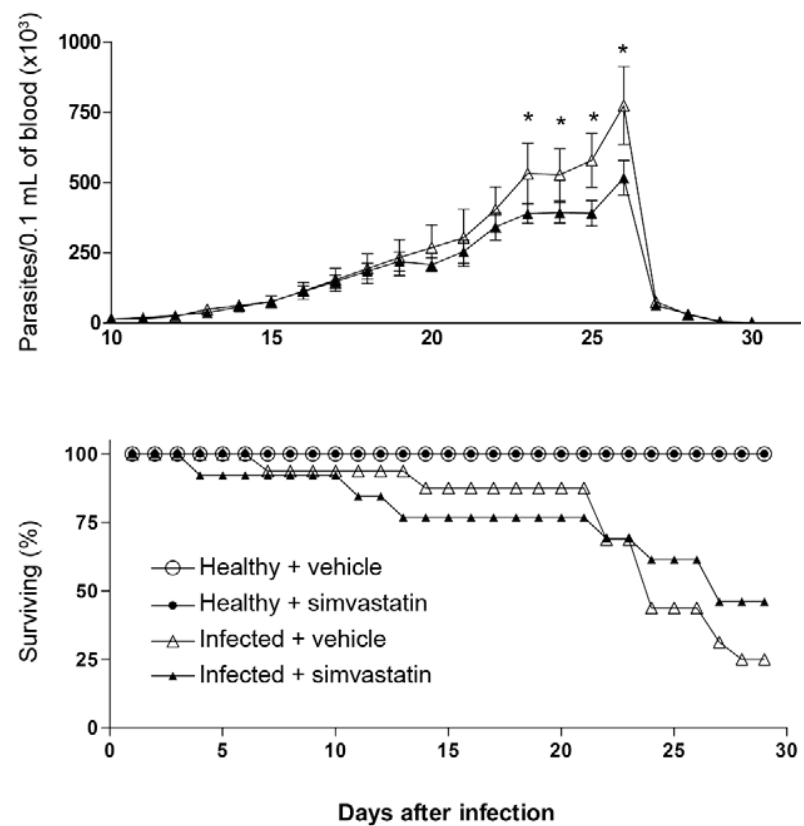

Fig. 1: simvastatin interferes in parasitemia and mice surviving. Daily treatment with $20 \mathrm{mg} / \mathrm{kg} /$ day of simvastatin reduced considerable the peak of parasitemia on the 26th day (A) and and increased the survive of animals till the peak of parasites on the 26th day (B) in comparison with those infected and non-infected mice without treatment. Data were shown as mean of each group/day plus standard error of the mean. Asterisk $(p<0.05)$ means statistical difference for each point of the curve.

TABLE

Representative number of blood parasites and percentage of mortality in C57BL/6 mice infected with Colombian strain of Trypanosoma cruzi during treatment with different concentrations of simvastatin

\begin{tabular}{|c|c|c|c|c|c|}
\hline & \multicolumn{5}{|c|}{ Infection with Colombian strain of $T . c r u z i$} \\
\hline & \multicolumn{4}{|c|}{ Simvastatin } & \multirow{2}{*}{$\begin{array}{c}\text { Untreated } \\
\begin{array}{c}- \\
\mathrm{n}=8\end{array}\end{array}$} \\
\hline & $\begin{array}{l}2 \mathrm{mg} \\
\mathrm{n}=8\end{array}$ & $\begin{array}{c}20 \mathrm{mg} \\
\mathrm{n}=8\end{array}$ & $\begin{array}{c}40 \mathrm{mg} \\
\mathrm{n}=8\end{array}$ & $\begin{array}{c}80 \mathrm{mg} \\
\mathrm{n}=8\end{array}$ & \\
\hline $\begin{array}{l}5 \text { th day } \\
\text { Mean of parasites }\left(\times 10^{3}\right)+\text { SEM } \\
\text { (\% of mortality) }\end{array}$ & $\begin{array}{c}10+2.7 \\
(0)\end{array}$ & $\begin{array}{c}7+3.3 \\
(0)\end{array}$ & $\begin{array}{c}12+3.3 \\
(0)\end{array}$ & $\begin{array}{c}33+4.8^{a} \\
(0)\end{array}$ & $\begin{array}{c}12+1.42 \\
(0)\end{array}$ \\
\hline $\begin{array}{l}15 \text { th day } \\
\text { Mean of parasites }\left(\times 10^{3}\right)+\text { SEM } \\
(\% \text { of mortality })\end{array}$ & $\begin{array}{c}367+89.3 \\
\quad(15)\end{array}$ & $\begin{array}{c}328+53.2 \\
(25)\end{array}$ & $\begin{array}{c}384+81.9 \\
(25)\end{array}$ & $\begin{array}{c}656+201 \\
\quad(25)\end{array}$ & $\begin{array}{c}450+36.9 \\
(25)\end{array}$ \\
\hline $\begin{array}{l}25 \text { th day } \\
\text { Mean of parasites }\left(\times 10^{3}\right)+\text { SEM } \\
\text { (\% of mortality) }\end{array}$ & $\begin{array}{c}1.060+153^{a} \\
(60)\end{array}$ & $885+92^{a}(40)$ & $\begin{array}{c}1.793+0.0 \\
\quad(90)\end{array}$ & $\begin{array}{l}0.0+0.0 \\
\quad(100)\end{array}$ & $\begin{array}{c}2.060+268 \\
(60)\end{array}$ \\
\hline
\end{tabular}

$a: \mathrm{p}<0.05$ when parasitemia was compared with untreated group; SEM: standard error of the mean. 
increased mortality in healthy animals and in those animals infected with $T$. cruzi this drug was able to protect $20 \%$ of the animals beginning on the 25 th day after infection (Fig. 1B) compared with untreated, infected mice.

In parallel, we evaluated whether simvastatin could be acting directly on parasite proliferation. Therefore, to eliminate any interference with the host cells (e.g., macrophages, Vero cells etc.), epimastigotes of T. cruzi were utilised to perform an in vitro evaluation in an axenic culture. Interestingly, simvastatin was efficient in reducing the epimastigotes present in culture in a dosedependent manner (Fig. 2).

Cholesterol levels and cardiac weight - High levels of circulating cholesterol were found in the serum of animals that were infected with $T$. cruzi. Low daily doses of simvastatin were able to modify this pattern in mice after 30 days of treatment (Fig. 3A). In contrast, because this study focused solely on the acute phase of the disease, simvastatin therapy was unable to prevent an increase in the relative weight of the heart of infected animals. This weight was evaluated by dividing the average of the mouse body weight by the heart weight (Fig. 3B).

Pleiotropic effects of simvastatin on cytokine and chemokine profiles - We investigated whether simvastatin therapy could shift the pattern of soluble inflammatory mediators upon murine T. cruzi infection. Serum homogenate levels of the inflammatory and regulatory cytokines IFN- $\gamma$, TNF- $\alpha$ and IL-10 (Fig. 4A, B, E) and chemokines CCL2 and CCL5 (Fig. 4 C, D), which are essential for the control of parasite infection and leukocyte recruitment to inflammatory foci, were increased in animals infected with $T$. cruzi after 30 days of infection. Interestingly, daily treatment with simvastatin drastically reduced the levels of inflammatory cytokines (Fig. 4A, B)

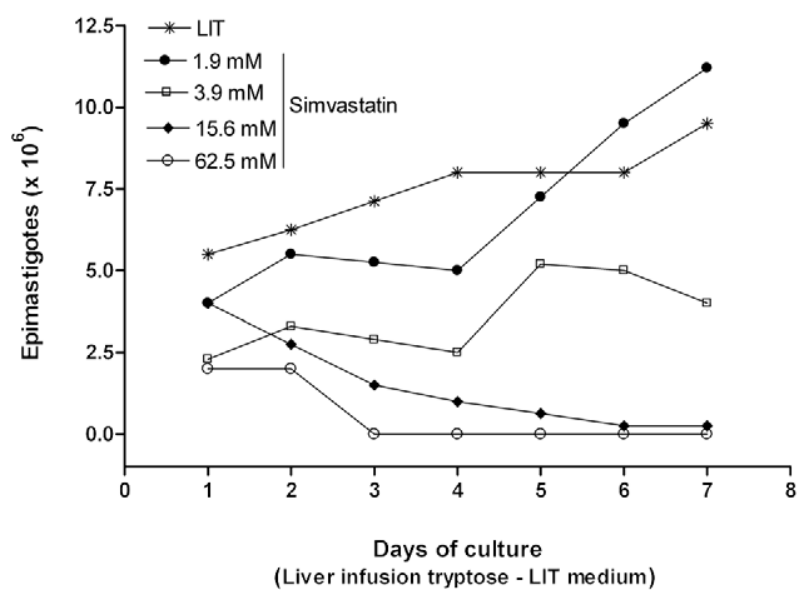

Fig. 2: simvastatin inhibits epimastigote proliferation in vitro. Epimastigotes forms of Trypanosoma cruzi was cultured in liver infusion tryptose medium in the presence of different concentrations of simvastatin $(1.9,3.9,15.6$ and $62.5 \mathrm{mM})$. Drugs were added $4 \mathrm{~h}$ after the insertion of parasites in the plates and daily counter of parasites shown a reduction in their proliferation in a dose-dependent way. Data were shown as a mean/standard error of the mean of two independent experiments. and chemokines (Fig. 4C, D). However, in these experiments, simvastatin did not statistically alter the level of the regulatory cytokine IL-10 in T. cruzi-infected mice or in uninfected animals (Fig. 4E). A similar investigation was performed on the supernatant from the cardiac tissue homogenate in which only inflammatory mediators were analysed. Again, simvastatin reduced the cardiac levels of TNF- $\alpha$ and IFN- $\gamma$ (Fig. 5A, B) and the chemokines CCL2 and CCL5 (Fig. 5C, D) in animals infected with T. cruzi.

Simvastatin alters amastigote nests and leukocyte infiltration into the heart - Inflammatory infiltration into the heart is partially driven by chemokine patterns and by the presence of T. cruzi or parasitic antigens inside or in close proximity to the myocardium. Here, treatment with simvastatin for 30 days drastically reduced the inflammatory cell infiltration into the heart tissue (Fig. 6B) compared with simvastatin-infected (Fig. 6A) and uninfected animals (Fig. 6C). Quantification of the nuclei in the cardiac tissue reinforced these histopathological observations; a significant reduction in inflammatory leukocytes in the heart tissue (Fig. 6D) and a reduction in the number of amastigote nests of T. cruzi (Fig. 6E) in animals treated with simvastatin was observed.
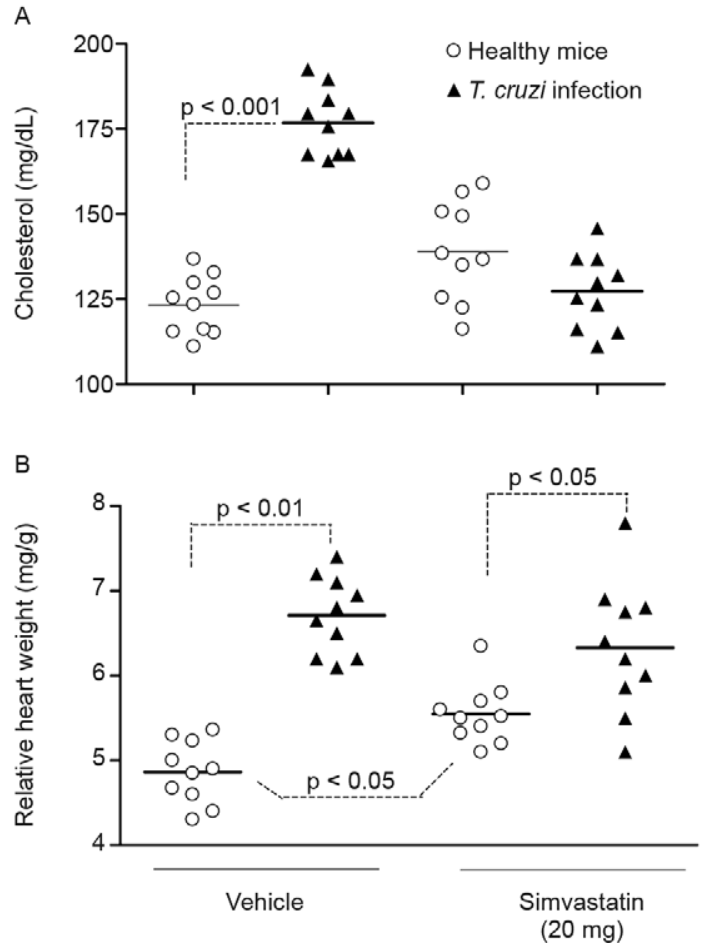

Fig. 3: simvastatin controls cholesterol in infected mice, but does not interfere in cardiac mass weight. Serum cholesterol level became stabilize in those Trypanosoma cruzi-infected animals without simvastatin therapy (A). In addition, the relative heart weight (B), calculated using heart weight in milligram/mouse body weight in gram $(\mathrm{mg} / \mathrm{g})$, did not present difference between infected groups even after 30 days of simvastatin treatment. It was used animals from two independent experiments $(\mathrm{n}=10)$. White circles mean groups of healthy mice and black triangles mice infected with T.cruzi. Data were shown as mean/ standard error of the mean and $p<0.05$ means statistical difference. 


\section{DISCUSSION}

The inflammatory process has been suggested to be the most important factor in acute and chronic Chagas disease, both in humans and experimental models (Lannes-Vieira et al. 2009, Talvani \& Teixeira 2011). However, this hypothesis does not exclude the participation of $T$. cruzi or parasitic antigens as a trigger for the inflammatory process. Additionally, the parasitic and the host genetic diversity have been suggested to be responsible for driving and modulating aspects of the inflammatory response (Santos et al. 2009, Guedes et al. 2010). Several researchers have consolidated their efforts to clarify whether this inflammatory process dictates the clinical changes and the progression toward chronic heart failure that is observed in humans. Therefore, cardiovascular drugs that are routinely used (e.g., ACE inhibitors, beta-blockers and others) have been tested for the treatment of Chagas disease. With a new anti-inflammatory focus, studies have demonstrated a drastic reduction in leukocyte infiltration in the heart, fibrosis, circulating inflammatory cytokines/chemokines and improvements in cardiac output ventricular functions in Chagas disease (Morris et al. 1989, Leon et al. 2003, Botoni et al. 2007, Coelho dos Santos et al. 2010, Paula-Costa et al. 2010). Because of these results, new therapeutic targets based on statins, a lipid-modifying agent HMG-CoA, have emerged as a method to prevent cardiovascular diseases (Liao 2002, Cheng et al. 2005, Mizuno et al. 2011). The clinical benefits of statins are thought to be associated with their ability to reduce cholesterol synthesis, but the product of their enzymatic reaction, mevalonate, is also a precursor of cholesterol and many non-steroidal isoprenoid compounds. The post-translational modification of mevalonate promotes membrane and protein-protein interactions and could result in the modification of numerous inflammatory signalling pathways that affect and modulate the cellular function of immune mediators (Quist-Paulsen 2010).
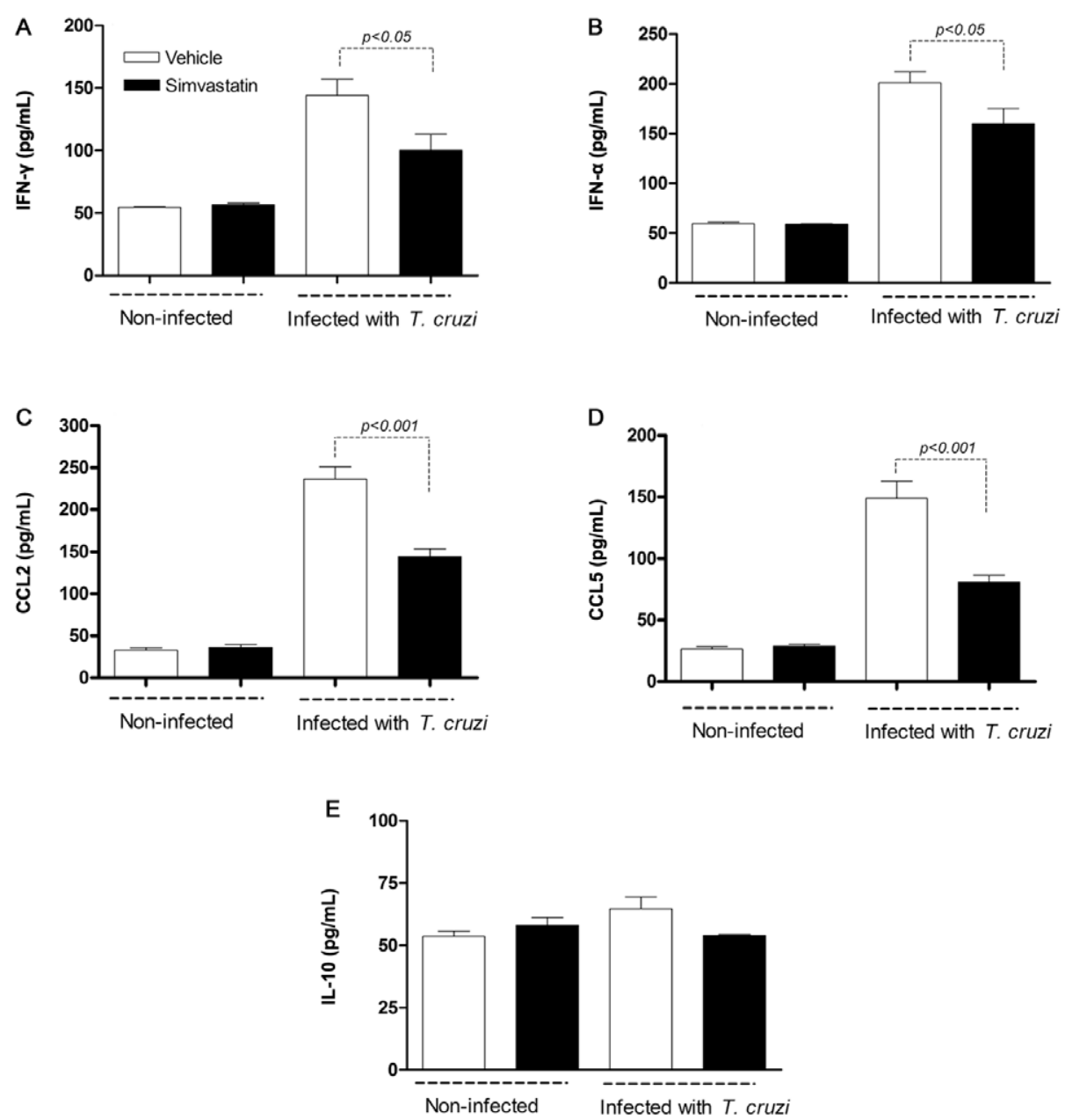

Fig. 4: simvastatin reduces serum levels of CCL2, CCL5 and proinflammatory cytokines. Treament with $20 \mathrm{mg}$ of simvastatin $/ \mathrm{kg} / \mathrm{mouse}$ daily decreased levels of proinflammatory cytokines interferon-gamma (IFN- $\gamma)(\mathrm{A})$, tumour necrosis factor-alpha (TNF- $\alpha)(\mathrm{B})$ and chemokines CCL2 (C) and CCL5 (D) while regulatory cytokine interleukin (IL-)10 (E) was not alternate in mice infected with Trypanosoma cruzi. Analysis was done between groups of animals treated with vehicle (white) and those treated with simvastatin (black) using animals from two independent experiments (total $\mathrm{n}=10$ ) and data were shown as mean/standard error of the mean. 
The pleiotropic effects of statins have previously been studied in the context of $T$. cruzi infection. Inhibition of the growth of epimastigotes of $T$. cruzi has been observed upon treatment with $10-0 \mathrm{mg} / \mathrm{mL}$ of statin (lovastatin) that may be a result of the inhibition of $\mathrm{C} 14$ acetate incorporation into parasite sterols (Florin-Christensen et al. 1990). T. cruzi, similar to many fungi and yeasts, requires specific sterols for its survival during different stages of its life cycle (Urbina 2009). In our in vitro investigation, the growth of cultured epimastigotes was reduced by the presence of simvastatin in a dose-dependent fashion $(1.9 \mathrm{mM}-2.5 \mathrm{mM})$. HMG-CoA reductase is already known to catalyse the NADPH-dependent reduction of HMG-CoA to mevalonate, which is primarily located in mitochondria. Therefore, simvastatin could potentially represent a competitive inhibitor of this enzyme in epimastigotes (in vitro) and in trypomastigotes (in vivo) (Hurtado-Guerrero et al. 2002).

The reduction in parasitaemia in mice using simvastatin $(20 \mathrm{mg} / \mathrm{kg} /$ daily) coincided with decreased mortality in animals after the 25th day of infection. Even with a significant reduction in the levels of inflammatory mediators, such as IFN- $\gamma$ and TNF- $\alpha, 30-40 \%$ mortality was expected in mice during peak parasitaemia based on the biological characteristics of the Colombian strain in isogenic C57BL/6 mice (Talvani et al. 2000, Paula-Costa et al. 2010). Unfortunately, mice do not survive well due to the alterations in the metabolic pathways that are a result of a persistent inflammatory response induced by specific strains of T. cruzi (Sánchez-Guillén et al. 2006), which is a limitation of this experimental model. However, mortality in our experimental model of Chagas disease could be delayed if we initiated a statin plus an anti-T. cruzi drug chemotherapeutic strategy, as previously demonstrated by Urbina et al. (1993). In this previous study, the authors indicated that lovastatin was able to potentiate the therapeutic effects of ketoconazole, an azolic anti-fungal drug. Additionally, combination therapy with both drugs at doses that offered only limited protection against $T$. cruzi was able to eliminate the presence of circulating parasites and prevent mortality (Urbina et al. 1993).

Investigations that have analysed the effect of statins on $T$. cruzi infection were only associated with chemotherapy or with the capacity of the drugs to block sterol (ergosterol) formation in parasites, thereby affecting parasitic growth or the capacity of the parasite to infect mammalian cells (Florin-Christensen et al. 1990, Urbina et al. 1993, Hankins et al. 2005, Priotto et al. 2009). Here, inflammatory cardiac disease in mice was analysed to measure the ability of simvastatin to reduce cholesterol in infected animals, to modulate the levels of systemic and cardiac pro-inflammatory cy tokines (IFN- $\gamma, \mathrm{TNF}-\alpha$ ) and chemokines (CCL2/MCP-1 and CCL5/RANTES) and to alter the heart inflammatory process at the end of the acute phase of the disease.

Based on our previous experience, an early anti-inflammatory intervention with simvastatin could be essential for the treatment of long-term cardiac inflammation and to reduce heart architectural and functional changes in experimental Chagas disease (Melo et al. 2011). A daily dose of simvastatin $(20 \mathrm{mg}$ ) was capable of reducing pro-inflammatory IFN- $\gamma$ and TNF- $\alpha$, but not regulatory IL-10 and did not ameliorate the clinical parameters (left ventricle ejection fraction and diastolic diameter of left ventricle) of dogs infected with $T$. cruzi during the
A

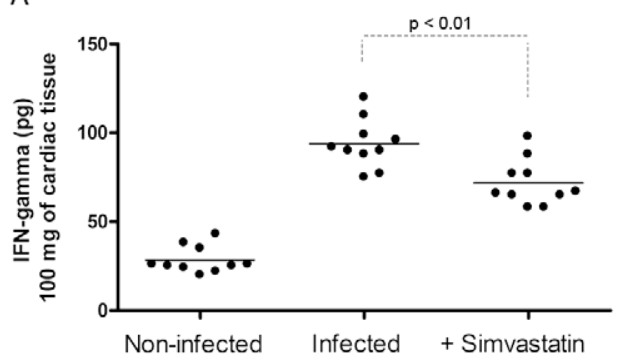

C

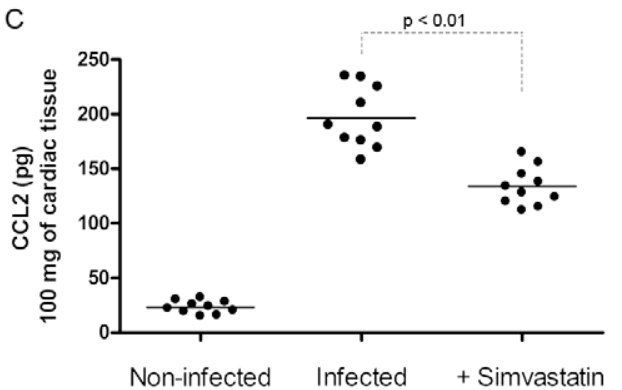

B

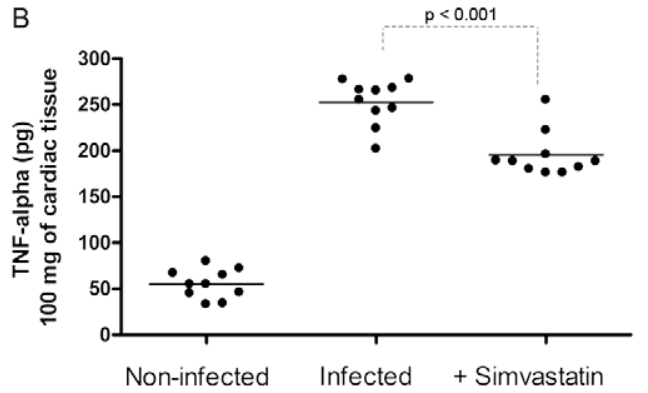

D

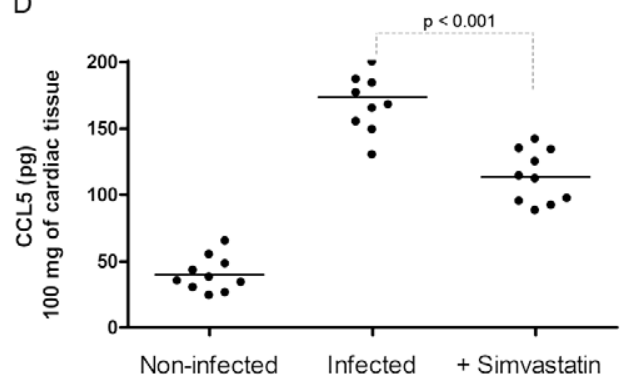

Fig. 5: heart tissue concentrations of interferon-gamma (IFN- $\gamma$ ) (A), tumour necrosis factor-alpha (TNF- $\alpha$ ) and cyitokines CCL2 (C) and CCL5 (D) in Trypanozoma cruzi-infected mice treated or not with simvastatin. Homogenate of $100 \mathrm{mg}$ of cardiac tissue from 10 animals were processed and inflammatory mediators (TNF- $\alpha$, IFN- $\gamma$, CCL2 and CCL5) were evaluated on the 30th day post-infection. Each dot represents the result in a single animal and the bar the mean value of the group. 
chronic phase of disease. We investigated the pleiotropic effects of simvastatin in mice because they are the most widely used species to investigate the immunology of the acute events of Chagas disease. In experimental Chagas disease, dogs have been useful in the study of cardiac parameters because of their similarities with human cardiac disease, but an increased understanding of inflammatory events (e.g., the chemokine network and cellular activation/recruitment) during the acute phase of Chagas disease has been well described in the murine model (Talvani \& Teixeira 2011). In addition, the reproducibility of these data in T. cruzi infection using two different mammalian models and different genetic populations of T. cruzi would reinforce the application of simvastatin as an immunomodulatory therapeutic agent.

In the murine model, some authors have suggested that some of the observed cardiac destruction is due to the presence of parasites in the heart tissue and an increase in leukocyte infiltration that leads to necrosis and fibrosis (Andrade 1983, Brener \& Gazzinelli 1997). The chemokines CCL2/MCP-1 and CCL5-RANTES have been largely associated with leukocyte (monocytes and lymphocytes) recruitment to inflammatory foci to combat parasite infection, but this infiltration inevitably results in damage to the host tissues (Aliberti et al. 1999, Talvani et al. 2000, Teixeira et al. 2002, Lannes-Vieira et al. 2009, Paiva et al. 2009). In fact, the role of CCL5 in the recruitment of $\mathrm{CCR}^{+}$leukocytes has been reinforced by experiments that indicate that CCR5-deficient mice are more susceptible to T. cruzi infection after the reduction of macrophages and T-cell migration into the heart, especially during the early stages of infection (Machado et al. 2005, Hardison et al.
2006). Other evidence of this phenomenon is based on the partial blockage of the CC-chemokine receptor inhibitor (Met-RANTES), which induces a reduction in the leukocyte influx (modulated by T. cruzi), followed by a reduction in parasitaemia and a reduction in fibronectin deposition in the heart tissue (Marino et al. 2004, Medeiros et al. 2009). Simvastatin was able to drastically reduce CCL2/ MCP-1 and CCL5/RANTES, thereby culminating in a reduction in the migration of inflammatory cells into the cardiac organ; this effect could be associated with a good cardiac prognosis in experimental models. Few studies involving statins and $T$. cruzi infection have focused on cardiac host inflammation, but simvastatin has previously been shown to be capable of reducing the expression and serum levels of CCL2/MCP-1 and CCL5/RANTES and CCR2 and CCR5 receptors in both in vitro and in vivo models of human immunodeficiency virus, vasculopathy and diabetes/metabolic diseases (Nabatov et al. 2007, Tsuchiya et al. 2007, Yin et al. 2007, Lin et al. 2009).

In conclusion, we have demonstrated for the first time that simvastatin has pleiotropic effects in modulating the systemic and cardiac levels of CCL2/MCP-1 and CCL5/ RANTES in isogenic mice infected with the cardiotropic strain of T. cruzi (Colombian). This therapeutic strategy also reduced the levels of circulating/tissue parasites, soluble inflammatory mediators (TNF- $\alpha$ and IFN- $\gamma$ ) and cardiac leukocyte infiltration during the acute phase of experimental disease. Therefore, given the key role of inflammation in the pathogenesis of Chagas disease, additional trials are needed in different experimental models to further support the use of statins as pharmacological agents to reduce cardiac inflammation in humans.
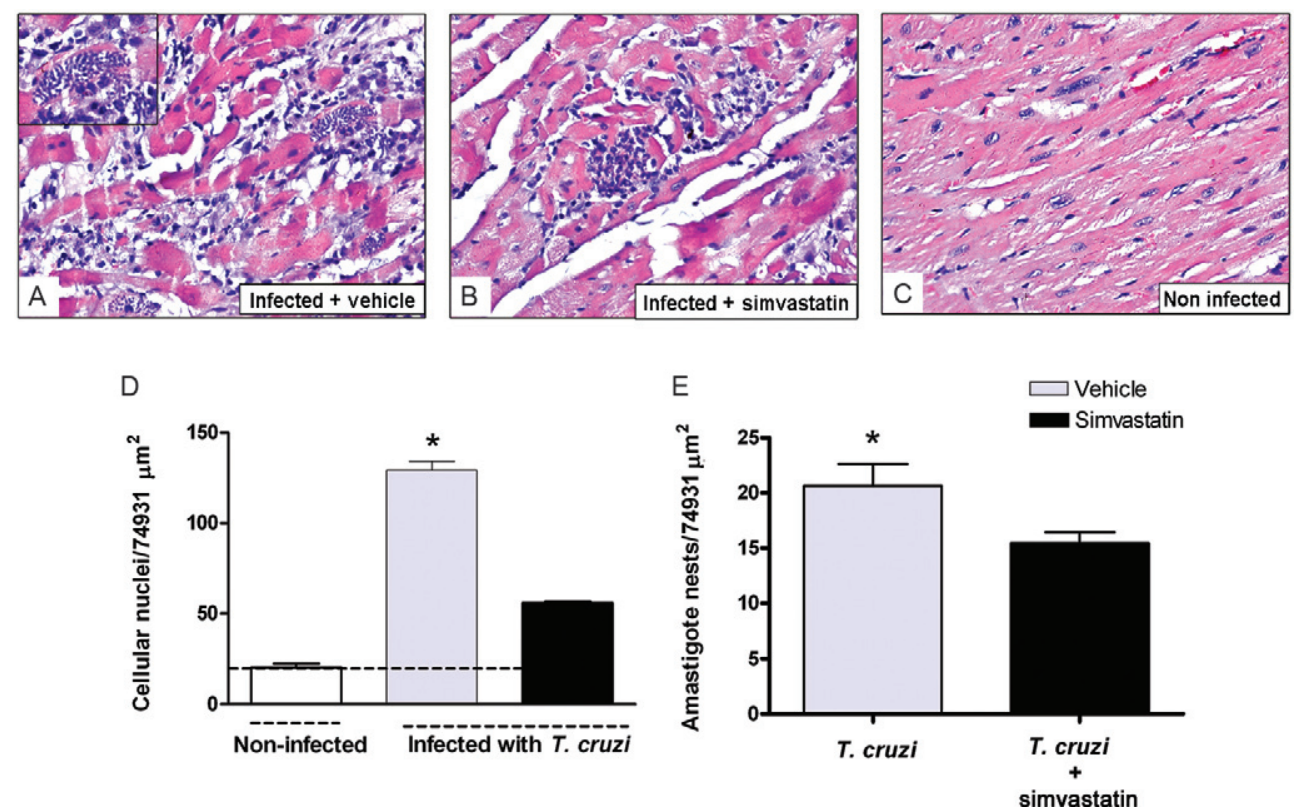

Fig. 6: inflammatory infiltration is reduced by treatment with simvastatin. Cardiac fragments were extracted from mice infected with Trypanozoma cruzi untreated (A) or treated with simvastatin (B) and from non-infected control group (C). Slides were stained with haematoxylin-eosin and cellular nuclei from inflammatory and resident cells (A, D) or amastigote nests (E and small square in A) counted using Leica QWin program in sections with 40X magnification. Data were obtained from survivors ( 2 independent experiments) at 30 days post-treatment and shown as mean/standard error of the mean. Asterisk $(\mathrm{p}<0.05)$ means statistical difference in comparison with infected group treated with simvastatin. 


\section{REFERENCES}

Aliberti JC, Machado FS, Souto JT, Campanelli AP, Teixeira MM, Gazzinelli RT, Silva JS 1999. Beta-chemokines enhance parasite uptake and promote nitric oxide-dependent microbiostatic activity in murine inflammatory macrophages infected with Trypanosoma cruzi. Infect Immun 67: 4819-4826.

Andrade ZA 1983. Mechanisms of myocardial damage in Trypanosoma cruzi infection. Ciba Found Symp 99: 214-233.

Brener Z, Gazzinelli RT 1997. Immunological control of Trypanosoma cruzi infection and pathogenesis of Chagas' disease. Int Arch Allergy Immunol 114: 103-110.

Botoni FA, Poole-Wilson PA, Ribeiro AL, Okonko DO, Oliveira BM, Pinto AS, Teixeira MM, Teixeira AL Jr, Reis AM, Dantas JB, Ferreira CS, Tavares WC Jr, Rocha MO 2007. A randomized trial of carvedilol after renin-angiotensin system inhibition in chronic Chagas cardiomyopathy. Am Heart J 153: e1-8.

Bu DX, Griffin G, Lichtman AH 2011. Mechanisms for the anti-inflammatory effects of statins. Curr Opin Lipidol 22: 165-170.

Caldas IS, Talvani A, Caldas S, Carneiro CM, de Lana M, da Matta Guedes PM, Bahia MT, 2008. Benznidazole therapy during acute phase of Chagas disease reduces parasite load but does not prevent chronic cardiac lesions. Parasitol Res 103: 413-421.

Cheng X, Liao YH, Zhang J, Li B, Ge H, Yuan J, Wang M, Lu B, Liu Y, Cheng Y 2005. Effects of atorvastatin on Th polorization in patients with acute myocardial infarction. The Europ J Heart Failure 7: 1099-1104.

Coelho dos Santos JS, Menezes CA, Villani FN, Magalhães LM, Scharfstein J, Gollob KJ, Dutra WO 2010. Captopril increases the intensity of monocyte infection by Trypanosoma cruzi and induces human T helper type 17 cells. Clin Exp Immunol 163: 528-536.

Cui X, Chopp M, Zacharek A, Roberts C, Lu M, Savant-Bhonsale S, Chen J 2009. Chemokine, vascular and therapeutic effects of combination simvastatin and BMSC treatment of stroke. Neurobiol Dis 36: 35-41.

Devaraj S, Rogers J, Jialal I 2007. Statins and biomarkers of inflammation. Curr Atheroscler Rep 9: 33-41.

Elrod JW, Lefer DJ 2005. The effects of statins on endothelium, inflammation and cardioprotection. Drug News Perspect 18: 229-236.

Florin-Christensen M, Florin-Christensen J, Garin C, Isola E, Brenner RR, Rasmussen L 1990. Inhibition of Trypanosoma cruzi growth and sterol biosynthesis by lovastatin. Biochem Biophys Res Commun 166: 1441-1445.

Greer JJ, Kakkar AK, Elrod JW, Watson LJ, Jones SP, Lefer DJ 2006. Low-dose simvastatin improves survival and ventricular function via e-NOS in congestive heart failure. Am J Physiol Heart Circ Physiol 291: H2743-H2751.

Guedes PM, Veloso VM, Talvani A, Diniz LF, Caldas IS, Do-ValleMatta MA, Santiago-Silva J, Chiari E, Galvão LM, Silva JS, Bahia MT 2010. Increased type 1 chemokine expression in experimental Chagas disease correlates with cardiac pathology in beagle dogs. Vet Immunol Immunopathol 138: 106-113.

Hankins EG, Gillespie JR, Aikenhead K, Buckner FS 2005. Upregulation of sterol C14-demethylase expression in Trypanosoma cruzi treated with sterol biosynthesis inhibitors. Mol Biochem Parasitol 144: 68-75.

Haraguchi FK, Pedrosa ML, Paula H, Santos RC, Silva ME 2010. Evaluation of biological and biochemical quality of whey protein. J Med Food 13: 1505-1509.

Hardison JL, Wrightsman RA, Carpenter PM, Kuziel WA, Lane TE, Manning JE 2006. The CC chemokine receptor 5 is important in control of parasite replication and acute cardiac inflammation following infection with Trypanosoma cruzi. Infect Immun 74: $135-143$.

Hurtado-Guerrrero R, Pena-Dias J, Montalvetti A, Ruiz-Perez LM, Gonzalez-Pacanowska D, 2002. Kinetic properties and inhibition of Trypanosoma cruzi 3-hydroxy-3-methylglutaryl CoA reductase. FEBS Letters 510: 141-144.

Lannes-Vieira J, Silverio JC, Pereira IR, Vinagre NF, Carvalho CME, Paiva CN, Silva AA 2009. Chronic Trypanosoma cruzi-elicited cardiomyopathy: from the discovery to the proposal of rational therapeutic interventions targeting cell adhesion molecules and chemokines receptors - how to make a dream come true. Mem Inst Oswaldo Cruz 104 (Suppl. I): 226-235.

Leon JS, Wang K, Engman DM 2003. Captopril ameliorates myocarditis in acute experimental Chagas disease. Circulation 107: 2264-2269.

Liao JK 2002. Isoprenoids as mediators of the biological effects of statins. J Clin Invest 109: 1594-1602.

Lin Y, Ye S, Chen Y, Li X, Yang GW, Fan A, Wang Y 2009. The effect of simvastatin on the serum monocyte chemoattractant protein-1 and intracellular adhesion molecule-1 levels in diabetic rats. J Diab Complications 23: 214-218.

Lula JF, Rocha MO, Nunes M do C, Ribeiro AL, Teixeira MM, Bahia MT, Talvani A 2009. Plasma concentrations of tumour necrosis factor-alpha, tumour necrosis factor-related apoptosis-inducing ligand, and FasLigand/CD95L in patients with Chagas cardiomyopathy correlate with left ventricular dysfunction. Eur $J$ Heart Fail 11: 825-831.

Machado FS, Koyama NS, Carregaro V, Ferreira BR, Milanezi CM, Teixeira MM, Rossi MA, Silva JS 2005. CCR5 plays a critical role in the development of myocarditis and host protection in mice infected with Trypanosoma cruzi. J Infect Dis 191: 627-636.

Marino AP, da Silva A, dos Santos P, Pinto LM, Gazzinelli RT, Teixeira MM, Lannes-Vieira J 2004. Regulated on activation, normal T cell expressed and secreted (RANTES) antagonist (MetRANTES) controls the early phase of Trypanosoma cruzi-elicited myocarditis. Circulation 110: 1443-1449.

Medeiros GA, Silverio JC, Marino AP, Roffe E, Vieira V, Kroll-Palhares K, Carvalho CE, Silva AA, Teixeira MM, Lannes-Vieira J 2009. Treatment of chronically Trypanosoma cruzi-infected mice with a CCR-1/CCR5 antagonist (Met-RANTES) results in amelioration of cardiac tissue damage. Microbes Infect 11: 264-273.

Melo L, Caldas IS, Azevedo MA, Gonçalves KR, Nascimento AFS, Figueiredo VP, Diniz LF, Lima WG, Torres RM, Bahia MT, Talvani A 2011. Low doses of simvastatin therapy ameliorate cardiac inflammatory remodeling in Trypanosoma cruzi-infected dogs. Am J Trop Med Hyg 84: 325-331.

Mizuno Y, Jacob RF, Mason RP 2011. Inflammation and the development of atherosclerosis: effects of lipid-lowering therapy. $J$ Atheroscler Thromb 18: 351-358.

Morris SA, Weiss LM, Factor SM, Bilezikian JP, Tanowitz H, Wittner M 1989. Verapamil ameliorates clinical, pathological and biochemical manifestations of experimental chagasic cardiomyopathy in mice. J Am Coll Cardiol 14: 782-789.

Nabatov AA, Pollakis G, Linnemann T, Paxton WA, de Baar MP 2007. Statin dirsupt CCR5 and RANTES expression levels in CD4(+) T lymphocytes in vitro and preferentially decrease infection of R5 versus X4 HIV-1. Plos ONE 23: e-470.

K, Fujita M, Kitakaze M, Hori M, Liao JK 2003. Short-term statin therapy improves cardiac function and symptoms in patients with idiopathic dilated cardiomyopathy. Circulation 19: 839-843. 
Paiva CN, Figueiredo RT, Kroll-Palhares K, Silva AA, Silvério JC, Gibaldi D, Pyrrho Ados S, Benjamim CF, Lannes-Vieira J, Bozza MT 2009. CCL2/MCP-1 controls parasite burden, cell infiltration and mononuclear activation during acute Trypanosoma cruzi infection. J Leukoc Biol 86: 1239-1246.

Paula-Costa G, Silva RR, Pedrosa MC, Pinho V, de Lima WG, Teixeira MM, Bahia MT, Talvani A 2010. Enalapril prevents cardiac immune-mediated damage and exerts anti-Trypanosoma cruzi activity during acute phase of experimental Chagas disease. Parasite Immunol 32: 202-208.

Prata A 2001. Clinical and epidemiological aspects of Chagas disease. Lancet Infect Dis 1: 92-100.

Priotto S, Sartori MJ, Repossi G, Valentich MA 2009. Trypanosona cruzi: participation of cholesterol and placental alkaline phosphatase in the host cell invasion. Exp Parasitol 122: 70-73.

Quist-Paulsen P 2010. Statins and inflammation: an update. Curr Opin Cardiol 25: 399-405.

Reis DD, Jones EM, Tostes S Jr, Lopes ER, Gazzinelli G, Colley DG, McCurley TL 1993. Characterization of inflammatory infiltrates in chronic chagasic myocardial lesions: presence of tumor necrosis factor-alpha ${ }^{+}$cells and dominance of granzyme $\mathrm{A}^{+}, \mathrm{CD} 8^{+}$lymphocytes. Am J Trop Med Hyg 48: 637-644.

Sánchez-Guillén MC, Bernabé C, Tibayrenc M, Zavala-Castro J, Totolhua JL, Méndez-Lopes J, González-Mejia ME, Torres-Rasgado E, Lópes-Colombo A, Pérez-Fuentes R 2006. Trypanosoma cruzi strains isolated from human, vector and animals reservoir in the same endemic region in Mexico and typed as T. cruzi I, discrete typing unit 1 , exhibit considerable biological diversity. Mem Inst Oswaldo Cruz 101: 585-590.

Santos DM, Martins TA, Caldas IS, Diniz LF, Machado-Coelho GL, Carneiro CM, Oliveira R de P, Talvani A, Lana M, Bahia MT 2009. Benznidazole alters the pattern of cyclophosphamide-induced reactivation in experimental Trypanosoma cruzi-dependent lineage infection. Acta Trop 113: 134-138.

Serrano CV Jr, Yoshida VM, Venturinelli ML, D’Amico E, Monteiro HP, Ramires JA, da Luz PL 2001. Effect of simvastatin on monocyte adhesion molecule expression in patients with hypercholesterolemia. Atherosclerosis 157: 505-512.
Talvani A, Ribeiro CS, Aliberti JC, Michailowsky V, Santos PV, Murta SM, Romanha AJ, Almeida IC, Farber J, Lannes-Vieira J, Silva JS, Gazzinelli RT 2000. Kinetics of cytokine gene expression in experimental chagasic cardiomyopathy: tissue parasitism and endogenous IFN-gamma as important determinants of chemokine mRNA expression during infection with Trypanosoma cruzi. Microbes Infect 2: 851-866.

Talvani A, Teixeira MM 2011. Inflammation and Chagas disease: some mechanisms and relevance. Adv Parasitology 76: 171-194.

Teixeira MM, Gazzinelli RT, Silva JS 2002. Chemokines, inflammation and Trypanosoma cruzi infection. Trends Parasitol 18: 262-265.

Tsuchiya A, Nagotani S, Hayashi T, Deguchi K, Sehara Y, Yamashita T, Zhang H, Lukic V, Kamiya T, Abe K 2007. Macrophage infiltration, lectin-like oxidized-LDL receptors-1 and monocyte chemoattractant protein-1 are reduced by chronic HMG-CoA reductase inhibition. Curr Neurovasc Res 4: 268-273.

Urbina JA 2009. Ergosterol biosynthesis and drug development for Chagas disease. Mem Inst Oswaldo Cruz 104 (Suppl.I): 311-318.

Urbina JA, Lazardi K, Marchan E, Visbal G, Aguirre T, Piras MM, Piras R, Maldonado RA, Payares G, de Souza W 1993. Mevinolin (lovastatin) potentiates the antiproliferative effects of ketoconazole and terbinafine against Trypanosoma (Schizotrypanum) cruzi: in vitro and in vivo studies. Antimicrob Agents Chemother 37: 580-591.

WHO - World Health Organization 2010. Chagas disease (American trypanosomiasis). Fact sheet 340. Available from: who.int/mediacentre/factsheets/fs340/.

Yin R, Zhu J, Shao H, Cheng X, Feng X, Li Z, Jing H 2007. Inhibition of chemokine receptor CCR2 and CCR5 expression contributes to simvastatin-induced attenuation of cardiac allograft vasculopathy. J Heart Lung Transplant 26: 485-493.

Zingales B, Andrade SG, Briones MRS, Campbell DA, Chiari E, Fernandes O, Guhl F, Lages-Silva E, Macedo AM, Machado CR, Miles MA, Romanha AJ, Sturm NR, Tibayrenc M, Schijman AG 2009. A new consensus for Trypanosoma cruzi intraspecific nomenclature: second revision meeting recommends TcI to TcVI. Mem Inst Oswaldo Cruz 104: 1051-1054. 